\title{
A Study on Training Qualified Physical Education Teachers in Rural Southwest China under the Current Compulsory Education System ${ }^{1}$
}

\author{
Liaokun Ye ${ }^{1}$, LianQiao $\mathrm{Du}^{2}$, Jun $\mathrm{Li}^{3}$, Sha Zhang ${ }^{4}$ \\ ${ }^{1}$ physical Education Department,Kunming, University of Science and technology, Kunming 650500, China \\ ${ }^{2}$ The 7th Primary School, Xiaguan, Dali, Yunnan Province (671000), China \\ ${ }^{3}$ physical Education Departmen, Kunming Medical University 650500, China \\ ${ }^{4}$ Yunnan Normal University, Institute of Physical Education, KunMing, 650500, China \\ 13388710989@163.com
}

\begin{abstract}
The quality issue has been the first and foremost concern on the part of the Chinese Ministry of Education in the process of implementing its compulsory education policy. As China's southwest is characterized as largely rural with the majority of the recipients being of minorities' background, compulsory education in this part of the country takes on unique features. Taking a perspective of compulsory education, this paper adopts the research methods of documentation, mathematical statistical method and logical analysis to investigate relative researches on developing qualified PE teachers in rural Southwest China. It is to analyze and explore the great responsibility of PE teachers under the background of the development of PE teachers of the rural compulsory education, which aims at providing a reference for improving the quality of PE teacher in rural areas.

Index Terms - Compulsory education; southwest of China; physical education teachers
\end{abstract}

\section{Introduction}

Bordering several countries, China's southwest is a vast frontier area inhabited by a large impoverished rural population consisting of some 30 ethnic minorities. As such, education in this region is for a big part directed to students of different ethnic minorities. However, the development of rural education is still in a dilemma. Therefore, rural education development virtually determines the education development of the whole Southwest area. The foundation of rural education is closely related to the building of qualified teachers, the development of compulsory education has always been of great importance of the Ministry of Education. In the great cause of building socialist modernization with Chinese characteristics, compulsory education is the foundation work of promoting the quality of the people of all ethnic groups and the construction of the modern civilized society, which requires the nation, society, schools and families make great efforts to promote, push forward, protect, and implement the strategic position of compulsory education as a top priority for development. Yunnan, Guangxi, Guizhou are large ethnic provinces with features of frontier, rural areas and ethnic groups. During the "Eleventh Five-Year Plan" period, the whole Yunnan province with total 129 counties all has achieved the goal of "Two bases", namely, basic implementation of the nine-year compulsory education and basic elimination of illiteracy among young and middle-aged people.

Up to the "Twelfth Five-Year Plan" period, Yunnan will vigorously improve the service of compulsory education to people of Yunnan's ethnic frontier areas, advance the balanced development of compulsory education in these areas, further consolidate the achievements and improve the quality of "Two bases".

\section{Research methodology}

2.1 Documentation: Search related documentary literature by using network and library resources to provide theoretical support for paper writing.

2.2 Mathematical Statistical Method: Use Mathematical Statistical Method to collect, analyze and interpret document and literature.

2.3 Logical Analysis : Lay the theoretical foundation for the paper's conclusion by logic analysis of the collected documents and statistical data.

\section{Research Finding and Analysis}

\subsection{Analysis and interpretation of the study on PE teachers of} the rural compulsory education.

Using "PE teachers of the rural compulsory education" as keyword to search articles through CNKI. net from the year 2000 to 2012, we found 15 related journal articles and 33 excellent master's theses. After reading and analysis these articles we found that these researches have focused on four areas: status quo of teachers, status quo of school physical education, status quo of $\mathrm{PE}$ teaching resources and countermeasures, study on professional education of $\mathrm{PE}$ teachers.

The research of status quo of teachers are mainly from the perspective of teachers' quantity, age, educational backgrounds, subject structure, knowledge level, scientific research ability, teachers' distribution and flow, etc., which come to the following conclusion: local education scale is decreasing; teachers' accessing mechanism is poor; there is

\footnotetext{
${ }^{1}$ This work is partially supported By the National Education Science "Twelfth Five" in 2012 subjects (FHB120496) support
} 
ineffective implementation of teachers' treatment, and shortage of education funds; management mechanism of teacher evaluation is imperfect, and limited employment schedule eventually lead to the lag development of PE teachers of rural compulsory education.

The study on professional education of PE teacher is mainly on the basis of combining investigation of present situation with summarizing problems, putting forward an observational view of breaking the traditional "Isolation" and "homogeneity". By rethinking and summarizing, these researches highlight the "Integration" of teachers' development. We should fundamentally find out the causes of brain drain of PE teachers and methodology of professional development of teachers to improve the quality of PE teachers of compulsory education.

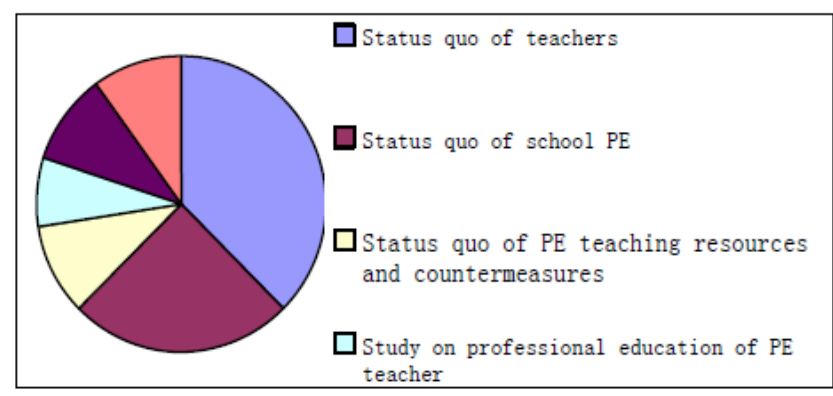

Fig. 1 Research contents of PE teachers of rural compulsory education

\subsection{Analysis of the development of PE teachers of rural compulsory education in Southwest China.}

Southwest China is a three-dimensional frontier area that integrates poverty, ethnicity and countryside as one unity. The development of rural education virtually determines the education development of the whole Southwest. Geographically, the Southwest China enjoys a large number of ethnic minority areas and border regions. Therefore, to improve the quality of compulsory education in Southwestern China not only lays the foundation for the overall development of compulsory education in China, but also contributes more to the exchanges of sport culture in border regions.

In 2010, central authorities' Proposal for Solving the Problems of Education of Ethnic Minority in Border Areas has clearly pointed out that the present education in frontier ethnic regions of our country is still relatively backward. We should resolutely implement the policies and measures of 2009 National Border Counties' Educational Development Seminar of Promoting Education Development in Border Counties. By 2020, education level in ethnic minority areas should reach the national level, especially the education level of borer counties. Meanwhile, the education level should surpass peripheral nations' education level.

In order to improve the education quality, we need to improve the quality of teachers. In addition, in accordance with the Regulations of School Physical Education and National Tentative Basic Standards of School Physical Education and Health Conditions, Primary and secondary schools must be equipped with full-time physical education teachers. These teachers must have a certain level of professional and technical level. PE teachers should be arranged by teaching hours of physical education in teaching program and the need of extra-curricular activities. Every 6 to 7 junior high schools' classes need one PE teacher, and one rural primary and secondary school with more than 200 students should be provided at least one full-time PE teacher.

Southwest China belongs to rural ethnic areas. During the stage of compulsory education, the development of the school physical education always receives little attention. Therefore, schools lacking of professional PE teachers is a common phenomenon. The phenomena that PE class often temporarily replaced by other subjects, that head teacher holds several posts at the same time including PE teacher, can be found everywhere. Few schools could meet the requirements of National Tentative Basic Standards of School Physical Education and Health Conditions.

\subsection{The role of PE teacher in the development of compulsory education.}

Compulsory education is not only the initial periods for students to receive education, but the germination periods for students to accept knowledge. In this case, school is a colorful mighty Kingdom in the eyes of students. Therefore, every teacher becomes an important figure in this kingdom and holds primary responsibility to inspire students' intelligence. Students' all-round development is the ultimate wish of parents. Sports not only enrich physical and mental pleasure, but also exploit intellectual development of adolescents. Several studies show that human potential especially memory is closely linked to temporary connection established by each part of the cerebral cortex. Scientific and reasonable physical exercise can improve the response speed of nerve cells in brain, analysis ability of the brain cortex, and comprehensive ability. From a physiological point of view, proper physical exercise can also improve physical function, enhance body immunity, improve the quality of the bone strength, and is good for young students' physical development. Professional PE teachers arrange the content of PE class in accordance with scientific exercise methods for primary and secondary school students. Physical education is compulsory in schools. Building professional PE teachers not only determines the physical development of adolescents, but also lays the foundation for the reservation of sport talents.

\subsection{Prospects of the construction of a contingent of rural PE teachers.}

First, we should clearly understand that the task of the construction of a contingent of rural PE teachers is practical work of compulsory education. Rural PE teachers are a group of greatest concern whether we regard them as extra development of teaching or a special group. This might be seen as a unique perspective in compulsory education. Thus, the establishment of the special "theory" of the construction of a contingent of rural PE teachers is particularly important. For example, to innovate the curriculum system and add practical exercises of in-service continuing education of rural $\mathrm{PE}$ 
teachers can enable the rural PE teachers to access to the most cutting-edge curriculum theory within a shortest time, which not only enables rural teachers to obtain the technical level as urban school teachers, but also makes rural PE teachers enjoy special development advantage of combining their learned knowledge with local condition and environment to innovate new appropriate rural PE teaching method.

Second, the fundamental PE teachers' brain-drain solution is for government to increase support and financial input to $\mathrm{PE}$ teachers, improve the facilities and the environment conditions of rural $\mathrm{PE}$, and strengthen the development quality of school PE.

Finally, comprehensively focusing on the construction and development of rural PE teachers is required. We will establish a complete and practicable improvement solution to analyze and deal with problems step by step. For example: we can start from the analysis of the basic situation of the construction of a contingent of rural teachers, historic analysis of the construction of a contingent of rural PE teachers, limitation analysis of the construction of a contingent of rural PE teachers, value analysis of the construction of a contingent of rural PE teachers, epistemology and methodology analysis of the construction of a contingent of rural PE teachers, to countermeasure analysis of the construction of a contingent of rural PE teachers.

\section{Conclusion}

(1) The research field of PE teachers of compulsory education in rural areas is uneven-distributed. They mainly focus on basic situation, and researches of how to improve the construction of a contingent of teachers are few.

(2) In accordance with the Regulations of School Physical
Education and National Tentative Basic Standards of School Physical Education and Health Conditions, the development of the construction of a contingent of PE teachers has always been of great importance to school physical education in the stage of compulsory education, it becomes the main aspects of improving the development quality of school physical education.

(3) Responsible for students' physical quality, PE teacher plays an important role in implementing the education policy of students' all-round development both in morality and physique.

(4) In China's geographical environment of "countryside surrounding city", rural education virtually determines the development of education in China. Addressing the problem of building rural $\mathrm{PE}$ teachers can not only fundamentally develop rural school PE, but also basically advance the education target of the growth and development of young students in a sound and scientific environment.

\section{References}

[1] Lu Xiaojie, The Current Situation and Countermeasures of Southwest Rural PE Development in Western Development Empirical Analysis, 2010.3

[2] Deng Yuening, Yang Ying, Li Feng, Research on Regional Disparity and Regional Development of Sichuan Rural PE Development, Journal of Chengdu Sport University, 2009 , 2(35)

[3] Wang Yuanyuan, Yang Yuanbo, Li Yijing, Tang Yiquan, Current Situation Investigation and Countermeasures of Rural PE in Guizhou Province, Journal of Beijing Sport University, 2006 , 1(29)

[4] Tian Huisheng, Thoughts on the Construction of Rural Teachers, China Social Sciences Press, 2010

[5] Tian Huisheng, Report on Balance Development of Compulsory Education 2010, Education Science Press, 2010 